\title{
AVALIAÇÃO DE IMPACTO AMBIENTAL EM UMA MATA CILIAR NA CIDADE DE MANAUS
}

\author{
Carlos André Sousa Almeida \\ MBA em Perícia, Auditoria e Gestão Ambiental \\ Cristhiane Carla Brandão Burlamaqui \\ MBA em Perícia, Auditoria e Gestão Ambiental
}

Franklin Silva de Araújo

MBA em Perícia, Auditoria e Gestão Ambiental

Jaime José Galisa de Lucena Júnior

MBA em Perícia, Auditoria e Gestão Ambiental

Josimar Ribeiro de Almeida

Escol Politécnica/UFRJ e Instituto de Química/UERJ

\section{RESUMO}

Com o crescente aumento da população urbana nos grandes centros, os problemas ambientais ocasionados por essa situação são cada vez mais comuns e com conseqüências mais graves. A cidade de Manaus também vem sofrendo com os problemas apresentados pela falta de preservação de suas matas ciliares, que vêm sendo alteradas e modificadas pela ação antrópica. Contudo, este trabalho tem como objetivo principal, estudar os impactos ambientais ocorridos em uma mata ciliar existente na zona urbana dessa cidade, em virtude da construção de um empreendimento de propriedade particular, bem como a valoração econômica decorrente de tais impactos. A elaboração foi feita em três etapas, sendo a primeira a identificação da área através de imagens de localização da área de preservação permanente, levantamento topográfico e manuseio de relatórios técnicos; a segunda foi o levantamento bibliográfico para sustentar as discussões provenientes dos levantamentos executados e dos resultados adquiridos, referentes à valoração de compensação ambiental (VECA) executada na área afetada; e a terceira parte foi a elaboração e aplicação do projeto de recuperação de área degradas (PRAD) para repor as perdas identificadas e promover a regeneração dessa área. Através das ferramentas empregadas, se pôde chegar à conclusão que a ação antrópica exercida pelo empreendimento afetou de forma negativa a área abordada, como o aumento da taxa de sedimentação à montante, alteração da concentração de sólidos, aumento na turbidez, e o surgimento de voçorocas ao longo de grande parte do leito do igarapé, trazendo conseqüentemente prejuízos à fauna e à flora local. Com a utilização de ferramentas matemáticas, pôde-se realizar o cálculo de valoração econômica de compensação ambiental, que indica um valor teórico que corresponde aos custos para compensar o que foi degradado na área. Em função da situação apresentada, elaborou-se o Plano de recuperação da área degradada, a fim de mitigar os efeitos negativos sofridos, onde as ações tomadas se mostraram bastante eficientes, em função dos resultados obtidos a médio e longo prazo 'rea impactada.

Palavras-chave: Mata ciliar, compensação ambiental, valoração econômica.

\section{ABSTRACT}

With the growing population in the large urban centres, environmental problems caused by it are increasingly common, with more serious consequences. Manaus CITY is also suffering with the problems presented by the lack of preservation of their gallery forests, which are being amended and modified by anthropic. However, this work has as main objective, to study the environmental impacts occurring in a riparian forest 
existing in the urban area of this city, because of the construction of a complex of a private property, and as a result of such valuation economic impacts. The compilation was done in three stages, the first one being the identification of the area through images of location of the area of permanent preservation, surveying and handling of technical reports; the second was the bibliographic survey to sustain the discussions from surveys performed in results acquired, referring to the valuation of environmental compensation executed in the affected area, and the third part was the development and implementation of the project of recovering area degradas to restore the losses identified and promote regeneration of this area. Through the tools employed, could be reached to the conclusion that the anthropic exerted by the enterprise to negatively affect the area addressed, such as improving the rate of sedimentation to the amount, change in the concentration of solids and increase in turbidity and the emergence of voçorocas over much of the bed of igarapé, thus bringing harm to local fauna and flora. With the use of mathematical tools, could be performed to calculate the economic valuation of environmental compensation, which indicates a theoretical value that corresponds to the costs to compensate for what has been degraded in the area. Depending on the situation presented, drafted up the Plan of recovery of degraded area, in order to mitigate the negative effects suffered, where the actions taken were very efficient, according to the results obtained in the medium and long term in the area impacted.

Key-words: Riparian forest, environmental compensation, economic valuation.

\section{INTRODUÇÃO}

Vislumbra-se que existem vários aspectos relacionados aos impactos ambientais provenientes principalmente da ausência de mata ciliar e, na maioria das situações voltadas para ocupação irregular do local, seja para moradias e/ou para instalação de edificações de interesses diversos.

Contudo, sendo a ação antrópica o principal mecanismo de causa e efeito dos impactos ambientais ocorridos em uma mata ciliar (área de preservação permanente), e neste contexto, existente dentro da zona urbana na cidade de Manaus, este estudo busca utilizar este aspecto como objetivo geral voltado para apontar mecanismos de minimização dos impactos ambientais existentes na área de preservação permanente, bem como para demonstrar o valor econômico da área em questão, viabilizando junto aos órgãos que integram as Políticas Públicas uma visão economicamente adequada às questões sociais e ambientais para o local. Utilizando uma metodologia aplicada ao uso de imagens satélites da área, levantamento bibliográfico e fotográfico, ad hoc analisados através de visitas in loco e através da fórmula matemática aplicada à valoração econômica de compensação ambiental - VECA, que servirão como instrumentos de complementação e suporte para direcionar as discussões, mecanismo facilitador absorvido dos resultados, garantindo uma conclusão baseada em fatores que viabilizem uma visão crítica sobre a problemática, baseada numa ótica sócio-econômico-ambiental que beneficiará a melhoria da qualidade de vida da sociedade.

A cidade de Manaus vem crescendo num ritmo muito acelerado e a visualização deste crescimento desordenado pode ser observada através das várias áreas invadidas, criadas sem planejamento urbano e que atualmente concentram em seu perímetro danos, 
impactos e riscos ambientais que prejudicam o desenvolvimento, social, econômico e os aspectos naturais da região.

\section{METODOLOGIA}

O presente trabalho foi realizado em três etapas, baseadas em instrumentos técnicos de análise documental e mediante visitas in loco. Sob estes aspectos aponta-se como etapa inicial a identificação da área através de imagens de localização da área de preservação permanente, levantamento topográfico e manuseio de relatórios técnicos que retratam a área como de preservação permanente submetida a processos erosivos, estreitamento das margens e do leito do igarapé, comprometimento do lençol freático. A visita realizada no local possibilitou um diagnóstico multidisciplinar e detalhado das características da área e seus aspectos positivos e negativos provenientes da retirada da mata ciliar.

O segundo momento deste estudo está associado ao levantamento bibliográfico para sustentar as discussões provenientes dos levantamentos executados e dos resultados adquiridos, referentes à valoração de compensação ambiental (VECA) executada na área afetada.

A etapa final consiste na aplicação do projeto de recuperação de área degradas (PRAD) para repor as perdas identificadas e promover a regeneração na área de preservação permanente.

\section{RESULTADOS}

A área de mata ciliar localizada dentro do perímetro urbano na cidade de Manaus, no bairro do São Geraldo a 0306'39,98" S e 6001'41,32" entre a Rua Madre Catarina Ronci e Comunidade da Vila do Preciosíssimo, na Av. Constantino Nery, como apresentado na figura 2. 


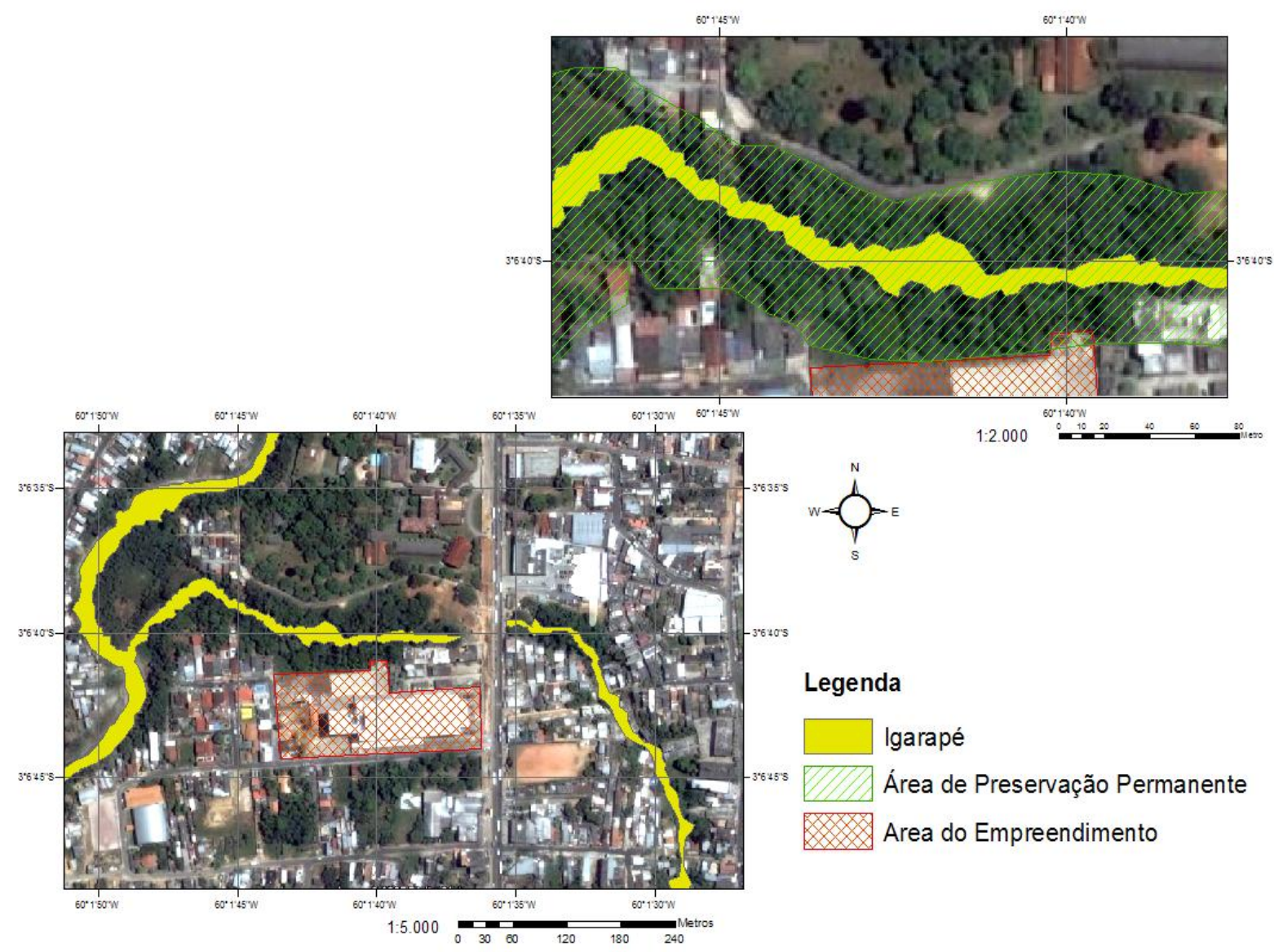

Figura 2 - Imagem de satélite da área de estudo.

Fonte: Google Earth.

Trata-se de uma área de preservação permanente, onde foram realizadas vistorias técnicas pelos órgãos ambientais no ano de 2005, a fim de averiguar danos e impactos ambientais no local, pelo fato do empreendimento ter construído uma estação de tratamento de efluentes invadindo parte do terreno destinado à área.

No diagnóstico ambiental elaborado in loco para constatar os reais impactos ambientais pode-se observar que, por conta de obras iniciais de instalação de uma Estação de Tratamento de Esgotos (ETE), houve atividade de remoção da vegetação local e movimentação do solo de forma mecanizada, causando poluição física, carreamento de material para o igarapé, bem como poluição paisagística, degradação da área de preservação permanente e do curso d'água local.

O curso d'água local se caracteriza como um ambiente lótico, de 1,60 metros de largura, de baixa ordem, afluente do igarapé da Cachoeira. Sua bacia drena extensa área urbana residencial, encontrando-se fortemente antropizado, vez que é receptor de efluentes de esgotos doméstico/sanitários e de águas pluviais proveniente da urbe em derredor.

No período de enchente suas águas sobem, em função do bloqueio provocado pelos igarapés de maior ordem e grande impermeabilização na área aumentando o escoamento 
superficial, quando da decorrência de fortes chuvas em sua área de drenagem podem provocar transbordamentos, e as enxurradas águas abaixo (velocidade de corrente e vazão) só podem ser atenuadas se as áreas de inundação de seu curso estiverem bem preservadas.

A movimentação parcial da vegetação ciliar do igarapé, em função da movimentação do solo para instalação da obra de implantação da ETE, acarretou os seguintes impactos ambientais, o aumento da taxa de sedimentação à montante, em vista do assoreamento causado, devido ao pontual aporte de sedimentos pedológicos terrestres para o interior do corpo d'água e devido a alterações da concentração de sólidos em suspensão e o aumento na turbidez.

A vegetação local encontrava-se, mesmo anterior à intervenção da obra bastante "antropizado".

A partir da identificação da disposição dos vegetais no sentido vertical, bem como da visão da floresta em perfil, considera que cada espécie vegetal tem seu limite de crescimento dentro da comunidade. Assim, cada camada formada por plantas tem aproximadamente a mesma altura na composição de um determinado tipo de vegetação.

Tal estudo é de fundamental importância para determinar qual a espécie mais adequada para o tipo de ambiente de baixio alterado. Foram identificadas poucas árvores emergentes, havendo predominância de palmeiras do tipo patauá (Oenocarpus bataua) e buriti (Mauritia flexuosa); sub-bosque com muitas ervas de áreas encharcadas com um dossel entre 10-20 m, sua fisionomia varia com o nível e tempo de encharcamento. Em áreas mais encharcadas e abertas pode ficar completamente dominada por palmeiras arbóreas. Em algumas áreas pode ocorre inundação periódica e algumas espécies típicas de várzeas e igapós podem ser encontrados.

Quanto à composição florística destacam-se algumas espécies arbóreas predominantes distribuídas no fragmento florestal. Fator importante para considerar na proposta de recuperação da área é a ocorrência de indivíduos nos diversos estágios de desenvolvimentos adultos, jovens e plântula. (Tabela 1).

Tabela 1 - Relação de espécies arbóreas predominantes na área do entorno à área de proteção permanente degradada e respectivas características ecológicas. Manaus 2005.

\begin{tabular}{l|l|l|l}
\hline FAMÍLIA & NOME CIENTIFICO & NOME POPULAR & CARACTERÍSTICAS ECOLÓGICAS \\
\hline CECROPIACEAE & $\begin{array}{l}\text { Cecropia } \\
\text { sciadophylla }\end{array}$ & Embaúba & $\begin{array}{l}10-15 \mathrm{~m} \text { de altura; pioneira, heliófita, } \\
\text { dispersão-zoocoria; de beira de rios; } \\
\text { frutos procurados pela avifauna e }\end{array}$ \\
\hline
\end{tabular}




\begin{tabular}{|c|c|c|c|}
\hline & & & preguiça. \\
\hline \multirow{2}{*}{ ARECACEAE } & Euterpe oleracea & Açaí do Para & $\begin{array}{l}\text { 10-20m de altura; pioneira, heliófita, } \\
\text { higrófita, dispersão-zoocoria; de } \\
\text { terrenos alagados; de valor } \\
\text { paisagístico. }\end{array}$ \\
\hline & Mauritia flexuosa & Buriti & $\begin{array}{l}\text { 15-25m de altura; heliófita, higrófita, } \\
\text { dispersão-baricoria; de áreas } \\
\text { brejosas ou permanentemente } \\
\text { inundadas; de valor paisagístico. }\end{array}$ \\
\hline LAURACEAE & Nectranda cuspidata & Canela do Mato & $\begin{array}{l}\text { 4-8m de altura; heliófita, higrófita, } \\
\text { pioneira; de áreas capoeira de beira } \\
\text { de rios; dispersão-zoocoria } \\
\text { (pássaros). }\end{array}$ \\
\hline BOMBACACEAE & Pachira aquática & Munguba & $\begin{array}{l}\text { 6-14m de altura; secundária, heliófita, } \\
\text { higrófita, dispersão-zoocoria- } \\
\text { autocoria, de beira de rios; frutos } \\
\text { procurados por várias espécies da } \\
\text { fauna. }\end{array}$ \\
\hline $\begin{array}{l}\text { LEGUMINOSEAE } \\
\text { MIMOSOIDEAE }\end{array}$ & Ingá Edulis Mart & Ingá Cipó & $\begin{array}{l}\text { 6-25m de altura; Planta Semidecídua, } \\
\text { Heliófita, Seletiva, Xerófita; Apresenta } \\
\text { dispersão espaço e descontínua ao } \\
\text { longo da área de distribuição; } \\
\text { Introduzida. }\end{array}$ \\
\hline
\end{tabular}

* Segundo PRANCE \& SILVA (1975), RIBEIRO et al. (1999) e LORENZI (2002)

Essa situação, associada à presença de sementes de espécies pioneiras no solo, aponta para alta resiliência do sistema o que contribuirá para a recolonização da área. A faixa de vegetação preservada ao longo do igarapé, da área degradada, será determinante para o processo de sucessão secundária, essa faixa, quando dotada de significativa vegetação, e interligadas com outras áreas e espaços verdes urbanos o fluxo de mobilidade dispersora da fauna e flora e propicia mais rapidamente a recolonização de um ambiente degradado.

\section{LEVANTAMENTO DOS IMPACTOS}

A avaliação dos impactos apresentados a partir deste detalhamento dos aspectos fisiográficos, nos dá uma visão das medidas que deverão ser aplicadas para recuperar o 
status original da área, mobilizando esta a um mecanismo de viabilidade econômica para o local e seu entorno, apresentando as seguintes, Tabela 2 (Identificação dos Impactos Ambientais negativos sobre o meio físico) e Tabela 3 (Identificação dos Impactos Ambientais negativos sobre o meio ambiente biológico).

Tabela 2 - Identificação dos Impactos Ambientais negativos sobre o meio físico.

\begin{tabular}{l|l}
\hline FATOR AMBIENTAL & IMPACTOS OBSERVADOS \\
\hline \multirow{2}{*}{ CONDIÇÕES CLIMÁTICAS } & $\begin{array}{l}\text { Possibilidade de alteração do microclima com conseqüências ao meio } \\
\text { ambiente. }\end{array}$ \\
\hline \multirow{5}{*}{ GEOLOGIA/GEOMORFOLOGIA } & $\begin{array}{l}\text { Instabilidade dos taludes marginais do local; } \\
\text { Mudanças na paisagem regional; } \\
\text { Desaparecimentos de parte de áreas de terras; } \\
\text { Degradação de solos para construção da estação de efluentes; } \\
\text { Intensificação dos processos erosivos, com decorrente assoreamento } \\
\text { e contaminação da água; } \\
\text { Desgaste do perfil do solo; } \\
\text { Impermeabilização do solo; } \\
\text { Formação de voçoroca; } \\
\text { Aumento escoamento superficial da água. }\end{array}$ \\
& $\begin{array}{l}\text { Transformação do meio hídrico; } \\
\text { Contaminação e eutroficação das águas; } \\
\text { Proliferação de macrófitas aquáticas; } \\
\text { Erosão das margens; } \\
\text { Receptor de efluentes de esgoto doméstico/sanitário; } \\
\text { Receptor de águas pluviais; } \\
\text { Aumento de sedimentos; } \\
\text { Alteração da concentração de sólidos em suspensão. }\end{array}$ \\
\end{tabular}

Tabela 3 - Identificação dos Impactos Ambientais negativos sobre o meio ambiente biológico.

\begin{tabular}{l|l}
\hline FATOR AMBIENTAL & IMPACTOS OBSERVADOS \\
\hline \multirow{2}{*}{ VEGETAÇÃO } & $\begin{array}{l}\text { Ação antrópico no local; } \\
\text { Desaparecimento de áreas florestais e de outras formações vegetais; } \\
\text { Presença de lixos urbanos. }\end{array}$ \\
\hline \multirow{3}{*}{ FAUNA TERRESTRE } & $\begin{array}{l}\text { Redução da fauna; } \\
\text { Alteração na composição da fauna; } \\
\text { Dispersores de sementes; } \\
\text { Predadores de insetos e outros. }\end{array}$ \\
\hline \multirow{3}{*}{ FAUNA AQUÁTICA } & $\begin{array}{l}\text { Interrupção da migração de peixes; } \\
\text { Alterações na composição da ictiofauna; } \\
\text { Prejuízos a outros animais aquáticos. }\end{array}$ \\
\hline
\end{tabular}




\section{Cálculo da valoração econômica para compensação ambiental da área}

A utilização dos recursos naturais pelo homem pode ser considerada como uma das causas de exaustão e degradação dos mesmos. Da forma como se dá, a realização de atividades produtivas e de consumo pode implicar em impactos ambientais capazes de suprimir sua utilização futura. Além da utilização de forma indevida dos recursos naturais existentes (que por sua vez são em grande maioria não-renováveis e não possuidores de substitutos) tem-se como problema o crescimento populacional e a elevação da atividade econômica, que são demandantes de maiores quantidades dos recursos naturais.

De acordo com MARTINS e FELICIDADE (2001), a valoração dos recursos ambientais seria um mecanismo eficaz para refletir no mercado os níveis de escassez de parte dos recursos naturais, propiciando condições para que a "livre" negociação nos mercados de commodities ambientais pudesse definir o nível ótimo de exploração e alocação desses recursos.

A valoração econômica dos recursos ambientais é fundamental para fixar a compensação financeira, correspondente aos impactos ambientais causados por empreendimentos ocorridos na fase de licenciamento ou já instalados. Serve para estabelecer as medidas mitigadoras necessárias, por se tratar de uma questão recente, os critérios econômicos para valoração ambiental necessitam de ajustes e aprimoramento metodológico caso a caso. O presente trabalho apresenta uma proposta de valoração econômica para compensação ambiental referente a uma área de preservação permanente existente numa mata ciliar na zona urbana da cidade de Manaus, a qual condiz com a seguinte fórmula (adotando-se o $\mathrm{R} \$$ como moeda):

\begin{tabular}{|c|c|}
\hline \multicolumn{2}{|c|}{ VECA $=(11+12+13+14+15) \times V_{\text {СомP }}$} \\
\hline $\mathrm{I}_{1}$ & Perda de área \\
\hline $\mathrm{I}_{2}$ & Perda de uso público \\
\hline $\mathrm{l}_{3}$ & Perda de produção de bens \\
\hline $\mathrm{I}_{4}$ & Perda de recurso ambiental \\
\hline $\mathrm{I}_{5}$ & Perda de serviço ambiental \\
\hline $\mathrm{V}_{\text {COMP }}$ & \% de compensação \\
\hline
\end{tabular}

$\mathrm{I}_{1}=\operatorname{AEMP} \times \mathrm{VV}$

AEMP $=$ Área de Influência do Empreendimento

$\mathrm{AEMP}=4 \mathrm{~F} 2+4 \mathrm{~F}(\mathrm{AE}) 1 / 2+\mathrm{AE}$

$\mathrm{F}=$ Faixa de Influência do Impacto Causado pela instalação /ou Edificação 
$\mathrm{AE}=$ Área de Instalação ou Edificação

$\mathrm{V} V=$ Valor Venal Médio de AE

$A_{E M P}=4 F^{2}+4 F(A E)^{1 / 2}+A E$

$A_{E M P}=4 \times(20)^{2}+4 \times 20 \times(52,5)^{1 / 2}+52,5 \mathrm{~m}^{2}$

$A_{E M P}=1600+2100+52,5$

$A_{E M P}=\mathbf{3 7 5 2 , 5} \mathbf{m}^{2}$

$\mathrm{I}_{1}=\mathrm{AEMP} \times \mathrm{VV}$

$\mathrm{I}_{1}=3752,5 \times 205,39$

$l_{1}=\mathbf{7 7 0 . 7 2 5 , 9 8}$

$I_{2}=($ AEMP / AUP $) \times$ VI $\times$ VN

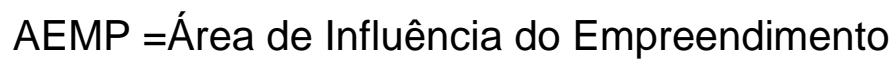

AUP =Área Afetada de Uso Público

$\mathrm{VI}=$ Valor de Ingresso ou Valor de Acesso

VN = Visitação Média Anual ou № Anual de Ingressos

$\mathrm{I}_{2}=($ AEMP / AUP $) \times$ VI $\times$ VN

$\mathrm{I}_{2}=(3752,5 / 0) \times 0 \times 0$

$\mathrm{I}_{2}=0$

$I_{3}=($ AEMP /AP) $\times$ PP

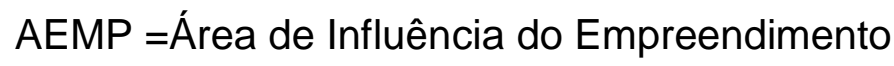

$\mathrm{AP}=$ Área de Produção de Bens

$\mathrm{PP}=$ Potencial Produtivo Estimado

$\left.\mathrm{l}_{3}=3752,5 / 4\right) \times 6$

$\mathrm{I}_{3}=\mathbf{5 6 2 8 , 7 5}$

$\mathbf{I}_{\mathbf{4}}=($ AEMP $/ A B H)$ PRA $\times \mathbf{V}$

AEMP =Área de Influência do Empreendimento

$\mathrm{ABH}=$ Área da Bacia Hidrográfica Impactada

PRA = Preço do Recurso Ambiental Desfrutável

$\mathrm{V}=$ Montante Desfrutável do Recurso Ambiental

$\mathrm{I}_{4}=0$ 
AEMP =Área de Influência do Empreendimento

$\mathrm{VE}=$ Valor dos serviços ambientais

$I_{5}=0$

Portanto, a Valoração Econômica para Compensação Ambiental apresenta o seguinte resultado:

VECA $=(11+12+13+14+15) \times V_{\text {COMP }}$

$\operatorname{VECA}=(770.725,98+0+5628,75+0+0) \times 30 \%$

$\mathrm{VECA}=\mathbf{2 3 2 . 9 0 6 , 4 2}$

\section{RECUPERAÇÃo DA ÁREA}

As matas ciliares são formações ribeirinhas com características vegetacionais definidas por uma interação complexa de fatores dependentes das condições ambientais ciliares. $O$ ambiente ribeirinho reflete as características geológicas, geomorfológicas, climáticas, hidrológicas, hidrográficas e da própria fragmentação antrópica dessa condição, que atuam como elementos definidores de paisagem e, portanto das condições ecológicas locais. Conhecidas igualmente como Ripárias ou de Galeria, desempenham funções muito importantes na manutenção da qualidade das águas, na estabilidade dos solos, na regularização dos regimes hídricos (manutenção de um fluxo menos flutuante ao longo do ano), na questão das cheias/inundações, no processo de controle do assoreamento dos rios, contribuindo, finalmente, para sustento da fauna aquática e ribeirinha. Possuem, ainda, importância vital para proteção dos mananciais, para controle dos nutrientes, sedimentos, adubos, agrotóxicos e erosão do solo sendo, por fim, importante na definição das características físicas, químicas e biológicas dos rios (RODRIGUES, 2000);

A sucessão ecológica é a substituição ordenada e graduada de uma comunidade por outra, até que se chegue a uma comunidade relativamente estável. A sucessão primária ocorre em substratos recém formados, envolvem modificações substanciais do ambiente causadas diretamente e indiretamente pêlos organismos pioneiros. A sucessão primária ocorre em áreas que não haviam sido ocupadas e/ou alteradas anteriormente por organismos. A sucessão secundária ocorre em comunidades preexistentes, seguindo a um distúrbio natural ou não. A evolução biológica de uma floresta (envelhecimento) se dá via diferentes grupos sucessionais (pioneira, secundária inicial, secundária tardia e clímax). Cada grupo sucessional possui suas próprias características quanto à 
composição florística, competição por luz, água, nutrientes e espaço, estratificação do dossel, importância ecológica das espécies, processo arquitetônico de construção da mata.

\section{Lista de Espécies}

Apresenta-se a seguir uma lista sugestiva de espécies nativas em função da disponibilidade em dois viveiros cadastrados no Ministério da Agricultura com responsável técnico pela produção das mudas (tabela 4)

Tabela 4 - Espécies florestais encontradas em viveiros de mudas localizados em Manaus, adequadas à área em questão:

\begin{tabular}{|c|c|c|c|c|}
\hline Família & & Nome Cinetífico & Nome Popular & Obs. \\
\hline ARECACEAE & & $\begin{array}{l}\text { Mauritia flexuosa } \\
\text { Euterpe oleracea } \\
\text { Oenocarpus bataua }\end{array}$ & $\begin{array}{l}\text { Buriti } \\
\text { Acaí do Para } \\
\text { Patauá }\end{array}$ & $\begin{array}{l}\text { Secundária } \\
\text { Pioneira } \\
\text { Atrativo a fauna }\end{array}$ \\
\hline GUTTIFERAE & & Rheedia gardneriana & Bacuri de Igapó & Atrativo a fauna \\
\hline MELIACEAE & & Carapa guianensis & Andiroba & $\begin{array}{ll}\text { Mata } & \text { primária } \\
\text { /secundária } & \end{array}$ \\
\hline BIGNONIACEAE & & Tabebuia sp. & Ipê & Valor paisagístico \\
\hline BOMBACACEAE & & Pachira aquática & Munguba & Atrativa a fauna \\
\hline $\begin{array}{l}\text { LEGUMINOSAE } \\
\text { CAESALPINIOIDEAE }\end{array}$ & - & Cássia leiandra & Ingá-mari & Pioneira \\
\hline $\begin{array}{l}\text { LEGUMINOSAE } \\
\text { MIMOSOIDEAE }\end{array}$ & - & Parkia nítida & Paricá & Secundária \\
\hline $\begin{array}{l}\text { LEGUMINOSAE } \\
\text { PAPILIONIDEAE }\end{array}$ & - & Dipteryx odorata & Camaru & Mata Primária \\
\hline
\end{tabular}

Fonte: Lorenzi, $\mathrm{H}(2002)$

\section{Aquisição de Mudas}

Um dos primeiros aspectos a considerar na recuperação de uma área degradada é a definição de espécies a serem utilizadas. Após a verificação da disponibilidade em viveiros locais e selecionadas aquelas que farão parte do elenco de espécies a serem utilizadas no plano, deverão ser contratados os fornecedores das mesmas. Tal preocupação tem por objetivo garantir a execução do arranjo (qualitativa e quantitativamente) definido. A seleção de espécies deve obedecer aos seguintes aspectos fitossanitários:

- As espécies plantadas devem proporcionar condições para o crescimento 
de outras espécies de interesse econômico ou conservacionistas;

- Não serem competidoras com as espécies a serem plantadas em etapas subseqüentes;

- O ciclo de crescimento e de reprodução deve ser conhecido para evitar que, através de dispersão de sementes ou propagação vegetativa indesejável, promova a exclusão de outras formas de vegetação.

- Que sejam incluídas espécies atrativas para a fauna silvestre, especialmente, morcegos e aves;

- Devem apresentar rápido crescimento e serem adaptadas a condições do ambiente;

- Que, preferencialmente, sejam espécies nativas da região, uma vez que estas se apresentem mais adaptadas às condições ambientais locais;

- Utilizar espécies que contribuam para o enriquecimento do solo, redução do risco de erosão e favoreçam a infiltração e água.

\section{Etapas do plano de recuperação}

Em função dos conceitos teóricos apresentados a opção de otimização é a regeneração natural, forma ecologicamente mais correta, sob o ponto de vista do incremento da diversidade biológica ao logo dos estágios sucessionais de recuperação da área degradada em questão. O sistema não correrá o risco de torna-se homogêneo, devido às ações de recolonização da área alterada e enriquecimento vegetal da área do entorno.

A área possui boa composição florística vizinha, vez que as ações de remoção da vegetação cessaram em tempo hábil, não se caracterizando em remoção total da vegetação. O solo local possui grande quantidade de sementes e plântulas que poderão favorecer o processo.

Considerando o tamanho da área degradada e a relativa resiliência do sistema, produto da matriz na qual se encontra inserida, optou-se pela estratégia de Restauração Sensu Lato associada ao enriquecimento da área. Para tanto, as etapas propostas consistiram em isolar a área, eliminar seletivamente ao desbastar as espécies competidoras, induzi e conduzir propágulos autóctones, adensar as espécies com transplantio de mudas e enriquecer a área com uso de mudas de espécies de interesse econômico e atrativo à fauna. 


\section{Obras de engenharia e medidas preventivas}

Antes de qualquer iniciativa de plantio das mudas, deverão ser concluídas as obras de engenharia (movimentação de terra, regularização do leito do igarapé, proteção de taludes com gramíneas).

A aceleração da recuperação natural pode ainda ser conseguido através do espalhamento uniforme do material lenhoso vegetal derrubado no solo local, com o fim de formação de material húmico, necessário ao enriquecimento do solo, pela decomposição microbiana. Esta pratica também favorece a formação de resistência física ao deslocamento superficial da água e conseqüentemente contenção de processos de erosão hídrica.

\section{Preparação para plantio das mudas}

As covas devem ser previamente marcadas em função do modelo utilizado, com tamanho de $0,40 \times 0,40 \times 0,40 \mathrm{~m}$. Após a abertura da cova deve-se proceder ao coroamento ao redor das mesmas, num raio aproximadamente 0,80m. A seguir deve-se efetuar a aplicação de calagem 30 a 40 gr/cova de calcário dolomítico e 1 a 2 Kg/cova de composto orgânico. A calagem deverá ser efetuada com pelo menos um mês de antecedência e a adubação uma semana antes do plantio.

\section{Aclimatação, preparação e plantio das mudas}

Adaptação das mudas às condições ambientais vigentes no local, visando o desenvolvimento de maiores condições de "pegamento". Tal prática consiste em depositar as mudas na proximidade da área de implantação, em local protegido, procedendo à redução da freqüência de irrigação e aumentando a incidência de luz. Aquelas mudas do entorno selecionadas para o transplantio deverão ser preparadas com o corte do torrão no estorno da planta (o tamanho do torrão pode varia com o tamanho da muda) e eliminação parcial da parte aérea (folhas) para compensar a perda de raízes e evitar o estresse hídrico.

O plantio das mudas ocorrerá, preferencialmente, no início, do período de chuvas e a distribuição das mesmas na área sujeita ao processo de enriquecimento ambiental deverá obedecer ao esquema representado graficamente no projeto. As Mudas mais frágeis deverão ser adequadamente tutoradas. Recomenda-se ainda, a colocação de cobertura morta na base da muda para favorecer a manutenção de umidade e redução do 
desenvolvimento de outras plantas.

\section{Monitoramento ambiental}

Vistoria periódica (mensal) para fins de verificação da implementação do projeto e correção de eventuais desvios, bem como nível e estabilização ambiental, estabelecimento de processo de regeneração natural, combate de pragas e doenças e eventuais podas.

\section{CONCLUSÃO}

Levando em consideração que a cidade de Manaus é abraçada por várias microbacias hidrográficas (igarapés) e que a cultura da população está associada a comunidades ribeirinhas, este recurso é utilizado como um instrumento de subsistência para fins de alimentação, lazer e higiene. Porém, devido ao crescimento abrupto da cidade, a partir da década de 60, com o advento do Pólo Industrial de Manaus - PIM, muitas moradias e empreendimentos se instalaram às margens dos igarapés e serviam-se dos "benefícios", que o recurso "gratuito" apresentava, tais como o abastecimento de água para banho, limpeza e alimentação. Além disto, são também visivelmente utilizados como redes de esgoto e depósito de lixo (resíduos descartados).

A qualidade da água é outro fator que agrega má qualidade de vida, devido à falta de infra-estrutura e saneamento básico, redes de esgoto são lançadas diretamente nos igarapés, contaminando os corpos d'águas superficiais e subterrâneos.

O impacto aferido ao solo torna-se mais evidente devido à falta de aderência por parte da mata ciliar que cumpria seu papel de reduzir tanto a velocidade das águas precipitadas quanto de infiltração por parte das raízes.

Num detalhamento mais sucinto sobre os impactos acarretados à fauna, pode-se constatar que os espécimes aquáticos (peixes, jacarés, aves), estão ameaçados pela ação antrópica caracterizada pelo descarte de águas residuais e servidas no igarapé que, os quais adaptados ao meio modificado, sobrevivem às condições adversas do ambiente, o que pode vir a acarretar de forma indireta, comprometimento na cadeia alimentar das espécies, principalmente ao Homem.

Levando-se em consideração os temas abordados, a valoração econômica para compensação dos impactos observados da mata ciliar em questão foi realizada com o auxílio de uma ferramenta matemática que quantifica alguns aspectos de grande relevância para a situação encontrada, como: a perda de área (I1) e a perda da produção 
de bens (I3). Outros aspectos não tiveram relevância na elaboração do cálculo como a perda de uso público (12), a perda de recurso ambiental (14) e a perda de serviço ambiental (15), por não terem contribuição significativa para a área abrangida. $\mathrm{O}$ valor observado de $R \$ 232.906,42$ (duzentos e trinta e dois mil e novecentos e seis reais e quarenta e dois centavos) indica um valor teórico que corresponde aos custos para compensar o que foi degradado na área.

Mediante a situação apresentada, tomou-se o Plano de Recuperação de Área Degradada (PRAD) como ferramenta de mitigação dos impactos ambientais ocorridos. Observou-se as ações a serem tomadas desde o seu planejamento até sua execução e acompanhamento dos resultados. Esta ferramenta se mostrou bastante eficiente, em função dos resultados obtidos a médio e longo prazos na área impactada.

\section{REFERÊNCIAS}

ALMEIDA, J. R.. Perícia Ambiental Judicial e Securitária, Dano passivo ambiental. Rio de Janeiro, Thex, 2006.

C. GASCON \& P. MUTINHO. Floresta Amazônica: Dinâmica, Regeneração e Manejo. Ministério da Ciência e Tecnologia: INPA: Manaus: 1998.

KAGEYAMA, P. \& GANDARA, F. B. Recuperação de Áreas Ciliares. In: RODRIGUES, R. R. \& LEITÃO FILHO, H. F. Matas Ciliares: Conservação e recuperação. São Paulo: EDUSP / FAPESP, 2000.

MARTINS, R.C., FELICIDADE, N. Limitações da Abordagem Neoclássica como Suporte Teórico para a Gestão de Recursos Hídricos no Brasil. In: FELICIDADE, N., São Carlos: Rima., 2001.

LORENZI, H. Árvores Brasileiras: Manual de Identificação e Cultivo de Plantas Arbores do Brasil. Vol. 1 Nova Odesa -OS: Instituto Plantarum.2002.

LORENZI, H. Árvores Brasileiras: Manual de Identificação e Cultivo de Plantas Arbores do Brasil. Vol. 2 Nova Odesa-OS: Instituto Plantarum.2002.

OLIVEIRA J. A Cidade de Manaus Visão Interdisciplinar. Manaus: EDUA, 2003.

RIBEIRO, J.E.L.S. et al. Flora da Reserva Ducke: Guia de Identificação das Plantas Vasculares de uma Floresta de Terra - Firme na Amazônia Central. Manaus: INPA 1999.

RIVAS, A. FREITAS, C. E. C. Amazônia: Uma Perspectiva Interdisciplinar. Manaus: UFAM, 2002.

RODRIGUES, R. R. \& GANDOLFI ,S. Conceitos, Tendências e Ações para Recuperação de Florestas Ciliares. In: RODRIGUES, R. R. \& LEITÃO FILHO, H. F. Matas Ciliares: Conservação e recuperação. São Paulo: EDUSP / FAPESP, 2000. 
RODRIGUES, R. R. Uma Discussão Nomenclatura das Matas Ciliares. In: RODRIGUES, R. R. \& LEITÃo FILHO, H. F. Matas Ciliares: Conservação e recuperação. São Paulo: EDUSP / FAPESP, 2000.

VIERA, L.S.; SANTOS, P.C.T.C. 1987. Amazônia: seus solos e outros recursos naturais. In: NIRO HIGUCHI et al. Projeto Jacarandá - Fase 2 Pesquisas Florestais na Amazônia Central. Manaus: INPA, 2003. 